\title{
On the Preparation of 2-Amino-4,5-dimethylbenzoic Acid and Related Compounds
}

\author{
ARNE BRÄNDSTRÖM and STIG A. I. CARLSSON
}

Chemical Research Laboratory, AB Hässle, Göteborg, Sweden

\begin{abstract}
2-Amino-4,5-dimethylbenzoic acid has been prepared by several different methods. The relative quantities of 3- and 4-monosubstitution products of $o$-xylene have been determined for the acetylation, bromination and chlorination reaction. The main nitration product of 3,4-dimethylacetophenone melting at $122^{\circ}$ has been found to be 3,4-dimethyl-2-nitroacetophenone and not 4,5-dimethyl-2-nitroacetophenone as proposed earlier by Buu-Hoî, Eckert and Royer. ${ }^{8}$
\end{abstract}

In connection with other work 2-amino-4,5-dimethylbenzoic acid was $I_{\text {needed in at least } 10 \mathrm{~kg} \text { quantities by a method which enables the prepara- }}$ tion of this acid in still larger quantities. It has previously ${ }^{1}$ been prepared by

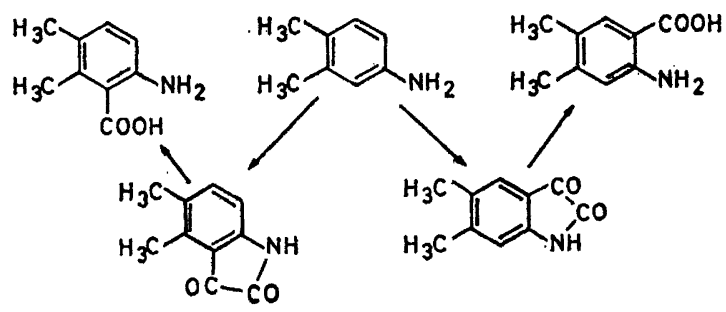

Scheme 1.

the reactions shown in Scheme 1. There are no serious problems involved in the separation of the isomers thus obtained, but the total yield is too low and the procedure is not convenient for a large scale preparation. Several other methods were therefore tried.

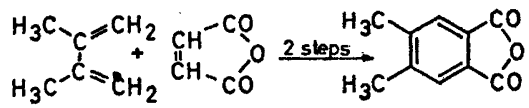<smiles>Cc1cc(C)c(C(=O)O)cc1N</smiles>

Scheme 2.

Acta Chem. Scand. 21 (1967) No. 4 
If 2,3-dimethylbutadiene were available in technical quantities the method shown in Scheme 2 might be the best one for the preparation of 2 -amino-4,5dimethylbenzoic acid.

At present, however, the only readily available starting material seems to be $o$-xylene or some of its monosubstitution products. Since many confusing results have been published about the monosubstitution of $o$-xylene some of these reactions have been studied.

The monosubstitution of o-xylene. The acetylation of $o$-xylene has been reported to give pure 3,4-dimethylacetophenone. ${ }^{2}$ This is correct since the product does not give the IR-absorption band at $770-800 \mathrm{~cm}^{-1}$ characteristic for 1,2,3-trisubstituted benzenes. ${ }^{3}$

Chlorination with chlorine has been reported to give a mixture of 1-chloro2,3-dimethylbenzene and 1-chloro-3,4-dimethylbenzene. ${ }^{4}$ In contrast to this, chlorination with sulphuryl chloride in the presence of $\mathrm{S}_{2} \mathrm{Cl}_{2}$ and $\mathrm{AlCl}_{3}$ has been reported, without any proof, to give only 1-chloro-2,3-dimethylbenzene. ${ }^{5}$ However, a quantitative IR determination of the relative quantities of the two isomers formed, shows that the same mixture of isomers is obtained in both processes.

The bromination of $o$-xylene has been reported 6 to give 1-bromo-3,4dimethylbenzene "of sufficient purity for most uses". A quantitative IR determination indicates, however, that the product is contaminated by $25 \%$ of 1-bromo-2,3-dimethylbenzene.

These results together with the results obtained by others in the nitration ? of $o$-xylene are given in Table 1.

Table 1.

\begin{tabular}{lcccc}
\hline Process & $\begin{array}{c}\text { Total yield } \\
\%\end{array}$ & $\begin{array}{c}\text { Fraction } \\
\text { 3-substitution }\end{array}$ & $\begin{array}{c}\text { Fraction } \\
\text { 4-substitution }\end{array}$ & References \\
\hline Acetylation & 96 & - & 1.00 & This paper \\
Bromination & 96 & 0.25 & 0.75 & $"$ \\
Chlorination & 65 & 0.43 & 0.57 & $"$ \\
Nitration & 79 & 0.58 & 0.42 & 7
\end{tabular}

Reactions starting with 3,4-dimethylacetophenone. Buu-Hoî, Eckert and Royer ${ }^{8}$ have reported that 4,5-dimethyl-2-nitroacetophenone, m.p. $120^{\circ}$, is formed in $75 \%$ yield by the nitration of 3,4-dimethylacetophenone. A reexamination of this reaction gave the result that a 2:1:1 mixture of the three possible isomers was obtained. It is thus impossible to obtain a $75 \%$ yield of any one isomer, but it is not difficult to obtain the main product in a pure state. It had a melting point of $122^{\circ}$ and is therefore identical with the product isolated by Buu-Hoî, Eckert and Royer ${ }^{8}$ and is 3,4-dimethyl-2-nitroacetophenone as seen from the reactions shown in Fig. 1 and from the NMR spectrum. The proof presented by Huu-Hoî, Eckert and Royer ${ }^{8}$ that their main 


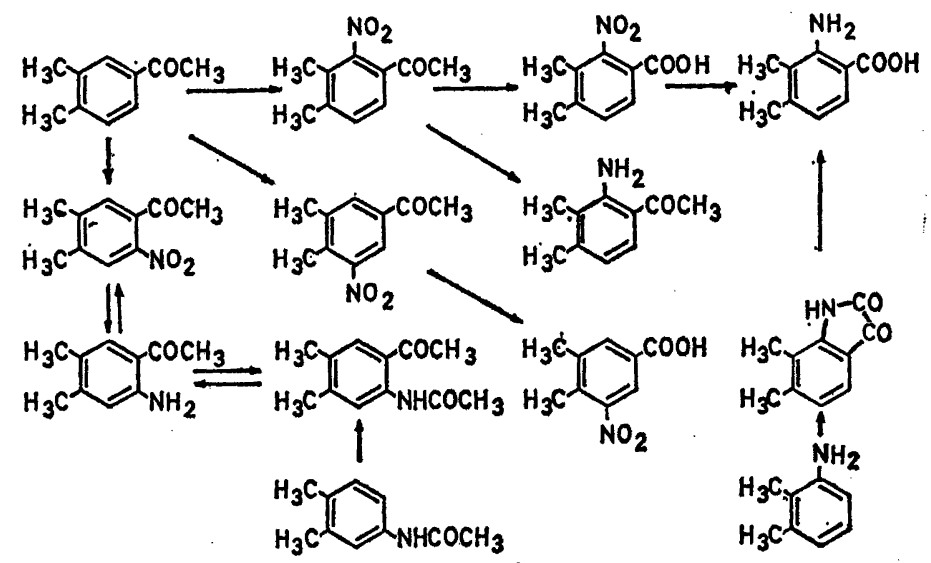

Fig. 1. Reactions starting with 3,4-dimethylacetophenone.

product melting at $120^{\circ}$ was 4,5-dimethyl-2-nitroacetophenone was impossible to repeat, but a compound with this structure was prepared from 2-amino-4,5dimethylacetophenone by replacing the amino group with a nitro group. This compound melted at $80^{\circ}$.

3,4-Dimethylacetophenone is thus nitrated in the same way as 3,4-dimethylbenzoic acid ${ }^{9}$ and offers no practicable method for the preparation of 2-amino-4,5-dimethylbenzoic acid.

Reactions starting with 1-chloro-3,4-dimethylbenzene. Pure 1-chloro-3,4-dimethylbenzene can be obtained from 3,4-dimethylaniline by the Sandmeyer method ${ }^{10}$ and the mixture obtained in the chlorination of 0 -xylene can be separated with a very efficient distillation column.

Friedel-Crafts acetylation gives 2-chloro-4,5-dimethylacetophenone in an excellent yield. This is oxidized with sodium hypochlorite to 2-chloro-4,5dimethylbenzoic acid in nearly quantitative yield and the acid is easily transformed to 2-amino-4,5-dimethylbenzoic acid by heating with aqueous ammonia and copper powder. This very satisfactory method is shown below $(\mathrm{X}=\mathrm{Cl})$.<smiles>[X]c1cc(C)c(C)cc1CCCCc1cc(C)c(C(=O)O)cc1CCCCc1cc(C)c(C(=O)O)cc1C</smiles>

Reactions starting with 1-bromo-3,4-dimethylbenzene. Pure 1-bromo-3,4-dimethylbenzene can be prepared from 3,4-dimethylaniline by the Sandmeyer method ${ }^{11}$ and a $75 \%$ pure product is formed in the bromination of $o$-xylene. This can be purified by a combination of column distillation and crystallization.

Friedel-Crafts acetylation gives 2-bromo-4,5-dimethylacetophenone which is readily oxidized by sodium hypochlorite to 2-bromo-4,5-dimethylbenzoic acid. This acid is easily obtained in a pure state even when the starting material 
is impure 1-bromo-3,4-dimethylbenzene. When this acid is heated with aqueous ammonia and copper powder 2-amino-4,5-dimethylbenzoic acid is formed in a good yield. These reactions are given above $(\mathrm{X}=\mathrm{Br})$.

Reactions starting with 3,4-dimethylacetanilide. 3,4-Dimethylacetanilide is readily obtained by the acetylation of 3,4-dimethylaniline with acetic anhydride ${ }^{12}$ or by the Beckmann rearrangement of 3,4-dimethylacetophenone oxime..$^{13}$. It is readily brominated to 2 -bromo-4,5-dimethylacetanilide ${ }^{14}$ and then converted to 2-amino-4,5-dimethylbenzoic acid by the reactions shown in Fig. 2.

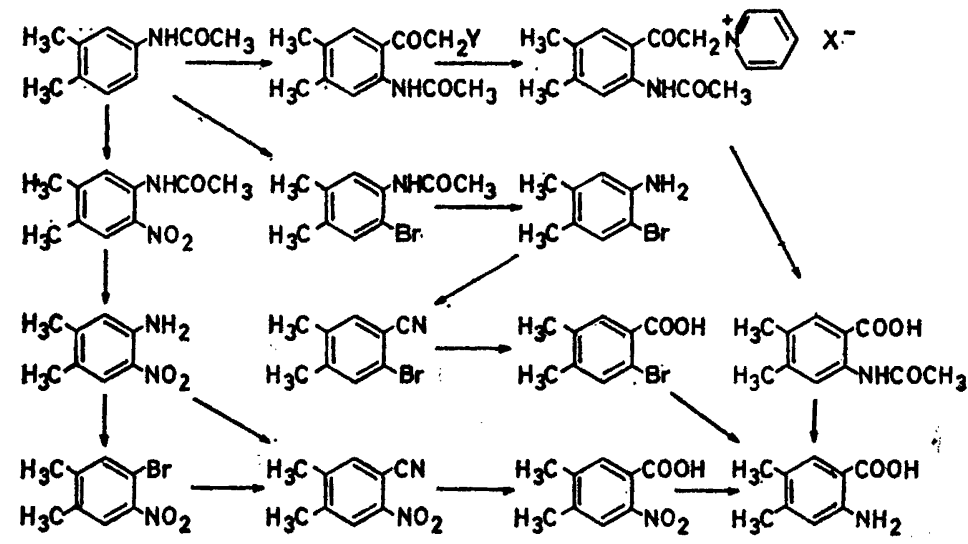

Fig. 2. Reactions starting with 3,4-dimethylacetanilide.

3,4-Dimethylacetanilide is also readily nitrated to 4,5-dimethyl-2-nitroacetanilide ${ }^{13}$ which can be transformed to 2 -amino-4,5-dimethylbenzoic acid by the reactions shown in Fig. 2.

Friedel-Crafts chloroacetylation of 3,4-dimethylacetanilide gives 2-acetamino-4,5-dimethylphenacylchloride in nearly quantitative yield. ${ }^{15}$ With pyridine this substance gives a quaternary pyridinium compound in excellent yield which is cleaved ${ }^{16}$ by sodium hydroxide to 2 -amino-4,5-dimethylbenzoic acid (Fig. 2, $\mathrm{X}=\mathrm{Y}=\mathrm{Cl}$ ) thus offering a very satisfactory method for the preparation of this acid.

3,4-Dimethylacetanilide is also readily acetylated by the Friedel-Crafts method to 2-acetamino-4,5-dimethylacetophenone which, by the action of iodine and pyridine, is converted to 2-acetamino-4,5-dimethylphenacylpyridinium iodide. This is cleaved in the same way as the corresponding chloro compound to 2-amino-4,5-dimethylbenzoic acid (Fig. 2, $\mathrm{Y}=\mathrm{H}, \mathrm{X}=\mathrm{I}$ ).

There are thus several satisfactory methods available for the preparation of 2-amino-4,5-dimethylbenzoic acid. 


\section{EXPERIMENTAL}

All melting points given are obtained on the Kofler Heizbank except those melting below $50^{\circ}$ for which a macro method was used.

3,4-Dimethylacetophenone was prepared by the Friedel-Crafts acetylation of $o$-xylene by the method of Szantay and Rohaly.13 This product had no IR absorption band in the region $770-800 \mathrm{~cm}^{-1}$ characteristic for 1,2,3-trisubstituted benzenes ${ }^{3}$ and is thus pure 3,4-dimethylacetophenone.

1.Chloro-2,3-dimethylbenzene was prepared in a pure state from 2,3-dimethylaniline by the Sandmeyer reaction. ${ }^{17}$ This product had strong characteristic IR absorption bands at $620,700,770$, and $838 \mathrm{~cm}^{-1}$.

1-Chloro-3,4-dimethylbenzene was prepared in a pure state from 3,4-dimethylaniline by the Sandmeyer reaction. ${ }^{10}$ This product had strong characteristic IR absorption bands at 438,542,650,808, and $879 \mathrm{~cm}^{-1}$, and a weak band at $698 \mathrm{~cm}^{-1}$. This is not due to contamination by 1-chloro-2,3-dimethylbenzene since there is no weak band at $770 \mathrm{~cm}^{-1}$ corresponding to the strongest band in the 1-chloro-2,3-dimethylbenzene spectrum.

Chlorination of o-xylene. $o$-Xylene was chlorinated by the introduction of one mole of chlorine into one mole of 0 -xylene containing $0.5 \%$ of iodine at both $+10^{\circ}$ and $-50^{\circ}$. The product was purified by washing with water, heating with a sodium hydroxide solution, drying and distilling at ordinary pressure. The monochlorination fraction was collected at $180-200^{\circ}$ and examined for 1-chloro-2,3-dimethylbenzene (using the IR band at $838 \mathrm{~cm}^{-1}$ ) and for 1-chloro-3,4-dimethylbenzene (using the band at $542 \mathrm{~cm}^{-1}$ ). $o$-Xylene was also chlorinated with sulphuryl chloride using the method reported by Dokukina and Koton ${ }^{5}$ to give only 1-chloro-2,3-dimethylbenzene.

The composition of the monochlorination fraction of all these preparations was essentially the same, viz. 58-59\% of 1-chloro-3,4-dimethylbenzene and $41-42 \%$ of 1-chloro-2,3-dimethylbenzene.

A monochlorination mixture containing $37 \%$ of 1-chloro-2,3-dimethylbenzene was distilled through a distillation column with 12-14 theoretical plates using a reflux ratio of $1 / 50$. The first few milliliters of the distillate contained $72 \%$ of 1 -chloro-2,3-dimethylbenzene. Calculations and practical experiments have demonstrated that a good separation of the two isomers can be obtained with a 45 plate bubble cup column. (Destillationstechnik Stage K.G., Köln-Niehl). 1-Chloro-3,4-dimethylbenzene is therefore an acceptable starting material.

1-Bromo-2,3-dimethylbenzene was obtained in a pure state from 2,3-dimethylaniline by the Sandmeyer reaction. ${ }^{18}$ This product had strong characteristic IR absorption bands at $608,700,768,830$, and $1000 \mathrm{~cm}^{-1}$.

1-Bromo-3,4-dimethylbenzene was prepared in a pure state from 3,4-dimethylaniline by the Sandmeyer reaction."1 This product had strong characteristic IR absorption bands at 802 and $860 \mathrm{~cm}^{-1}$ and weaker bands at 435, 532, 625, 693, 990, and $1018 \mathrm{~cm}^{-1}$. The band at $693 \mathrm{~cm}^{-1}$ is not due to contamination by 1 -bromo-2,3-dimethylbenzene.

Bromination of o-xylene was performed by the method in Organic Syntheses. ${ }^{6}$ This product was analysed and found to consist of $25 \%$ 1-bromo-2,3-dimethylbenzene (using the IR band at $830 \mathrm{~cm}^{-1}$ ) and $75 \%$ 1-bromo-3,4-dimethylbenzene (using the band at $\left.532 \mathrm{~cm}^{-1}\right)$. This mixture was distilled through a fractionation column with $12-14$ theoretical plates using a reflux ratio of 1/50. The content of 1-bromo-2,3-dimethylbenzene in the first few milliliters of the distillate was $35 \%$. A calculation shows that the separation of the two isomers by distillation is very difficult.

The monobromination mixture was chilled to below $-25^{\circ}$. The crystals formed were collected by filtration at low temperature and found to consist of almost pure 1-bromo-3,4-dimethylbenzene. Using a combination of distillation and crystallization 1-bromo-3,4-dimethylbenzene can thus be obtained.

3,4-Dimethylacetanilide was prepared from 3,4-dimethylaniline ${ }^{12}$ or from 3,4-dimethylacetophenone oxime. ${ }^{13}$ 


\section{Reactions starting with 1-chloro-3,4- dimeth y l benzene}

2-Chloro-4,5-dimethylacetophenone. In a 2-litre three-necked flask fitted with a stirrer, a reflux condenser, and a dropping funnel, $55 \mathrm{ml}$ of acetyl chloride was added to a mixture of $95 \mathrm{~g}$ of $\mathrm{AlCl}_{3}, 90 \mathrm{~g}$ of 1-chloro-3,4-dimethylbenzene, and $600 \mathrm{ml}$ of carbon disulphide. The mixture was then stirred for $2 \mathrm{~h}$. The resulting solution was poured into ice, the layers separated, and the carbon disulphide evaporated. The residue was distilled at $135-138^{\circ} / 12$ $\mathrm{mm}$ Hg. This product had a m.p. of $14^{\circ}$. The yield was $105 \mathrm{~g}$. NMR analyses indicated that this product contained $2 \%$ impurities. The NMR and IR spectra were in agreement with the structure proposed.

2-Chloro-4,5-dimethylbenzoic acid. A solution of sodium hypochlorite was prepared from $246 \mathrm{~g}$ of sodium hydroxide, $340 \mathrm{ml}$ of water, $830 \mathrm{~g}$ of ice, and $182 \mathrm{~g}$ of chlorine. This solution was transferred to a 3-litre three-necked flask fitted with a stirrer, a reflux condenser, and a dropping funnel. $0.5 \mathrm{~g}$ of sodium laurylsulphonate was added and the solution heated to $70^{\circ}$. To the rapidly stirred solution $100 \mathrm{~g}$ of 2 -chloro-4,5-dimethylacetophenone was added at $70-75^{\circ}$. The stirring was continued for half an hour and the excess of hypochlorite destroyed by the addition of sodium pyrosulphite. The hot solution was transferred to a beaker and acidified with conc. hydrochloric acid. The mixture was cooled, the product filtered off, dried and recrystallized from toluene. The yield was $98 \mathrm{~g}$ and the m.p. $184^{\circ}$. The equivalent weight was 186.0 , calc. 184.6 , and the chlorine content $19.26 \%$, calc. $19.20 \%$. The NMR spectrum was in agreement with the structure proposed.

2-Amino-4,5-dimethylbenzoic acid hydrochloride. A mixture of $44 \mathrm{~g}$ of 2-chloro-4,5dimethylbenzoic acid, $16.8 \mathrm{~g}$ of potassium hydroxide, $250 \mathrm{ml}$ of concentrated ammonia, and $1 \mathrm{~g}$ of copper powder was heated in an autoclave at $145^{\circ}$ for $2 \mathrm{~h}$. The resulting solution was evaporated to dryness. $150 \mathrm{ml}$ of water was added and the mixture strongly acidified with $100 \mathrm{ml}$ conc. hydrochloric acid. The resulting mixture was heated in a boiling water bath, filtered hot and poured directly into a solution of $110 \mathrm{~g}$ of anhydrous sodium acetate in $200 \mathrm{ml}$ of water. The amino acid was collected by filtration, washed with water and dried. It was then dissolved in acetone, the solution filtered and the hydrochloride precipitated by the addition of hydrogen chloride. The yield was $29 \mathrm{~g}$. A portion of this product was dissolved in water containing some hydrochloric acid and precipitated with sodium acetate. The product was recrystallized from alcohol. 2-Amino-4,5-dimethylbenzoic acid, m.p. $215^{\circ}$, lit. ${ }^{1} 213-214^{\circ}$, was obtained.

\section{Reactions starting with 1-bromo-3,4- dimethylbenzene}

2-Bromo-4,5-dimethylacetophenone. To a solution of $94 \mathrm{~g}$ of acetyl chloride and $185 \mathrm{~g}$ of 1-bromo-3,4-dimethylbenzene in $600 \mathrm{ml}$ of carbon disulphide in a 2-litre threenecked flask fitted with a stirrer, a reflux condenser and a stopper, $147 \mathrm{~g}$ of $\mathrm{AlCl}_{3} \mathrm{was}$ added in one portion. The mixture was then refluxed for $2 \mathrm{~h}$. The resulting solution was poured onto ice, the layers separated and the solvent evaporated. The residue was distilled yielding $182 \mathrm{~g}$ of 2 -bromo-4,5-dimethylacetophenone, b.p. $135-138^{\circ} / 6 \mathrm{~mm} \mathrm{Hg}$. Recrystallization from petroleum ether gave a product with m.p. $31-32^{\circ}$. NMR and gas chromatographic analyses indicated that this product was pure and the NMR spectrum was in agreement with the structure proposed.

When acetyl chloride was slowly added to a mixture of 1-bromo-3,4-dimethylbenzene, $\mathrm{AlCl}_{3}$ and carbon disulphide, a low boiling forerun which is probably 3,4-dimethylacetophenone was obtained in the distillation.

2-Bromo-4,5-dimethylbenzoic acid. By the method described in detail for 2-chloro-4,5dimethylbenzoic acid, 2-bromo-4,5-dimethylbenzoic acid, m.p. $196^{\circ}$, lit. $^{19} 195-196^{\circ}$, was obtained by the oxidation of 2-bromo-4,5-dimethylacetophenone with sodium hypochlorite.

2-Amino-4,5-dimethylbenzoic acid. Treatment of 2-bromo-4,5-dimethylbenzoic acid with aqueous ammonia by the method described in detail using 2-chloro-4,5-dimethylbenzoic acid gave 2-amino-4,5-dimethylbenzoic acid. 


\section{Reactions starting with 3,4-dimethylacetanilide}

2-Bromo-4,5-dimethylacetanilide was prepared by the bromination of 3,4-dimethylacetanilide using the method of Mills and Nixon. ${ }^{14}$

2-Bromo-4,5-dimethylaniline hydrochloride. $172 \mathrm{~g}$ of 2-bromo-4,5-dimethylacetanilide was refluxed with a solution of $250 \mathrm{ml}$ of hydrochloric acid in $250 \mathrm{ml}$ of alcohol for $3 \mathrm{~h}$. The mixture was chilled and the product collected by filtration and washed with cold alcohol. The yield was $161 \mathrm{~g}$ of colourless crystals.

The free aniline obtained by the addition of a base to a solution of this hydrochloride in water had m.p. $85^{\circ}$, lit. ${ }^{14} 84.5^{\circ}$.

2-Bromo-4,5-dimethylbenzonitrile. $47.3 \mathrm{~g}$ of 2-bromo-4,5-dimethylaniline hydrochloride was dissolved in $20 \mathrm{ml}$ of concentrated hydrochloric acid and $100 \mathrm{ml}$ of water. The hot solution was chilled to $0^{\circ}$ and diazotized with a solution of $14 \mathrm{~g}$ of sodium nitrite in $40 \mathrm{ml}$ of water at a temperature of $0-5^{\circ}$. The resulting diazonium solution was slowly added at $0-5^{\circ}$ to a mixture of 25 of cuprous cyanide, $10 \mathrm{~g}$ of anhydrous sodium carbonate, $32.5 \mathrm{~g}$ of sodium cyanide, $150 \mathrm{ml}$ of water, and $50 \mathrm{ml}$ of toluene. After standing overnight the mixture was heated to $50^{\circ}$ and the product dissolved by the addition of toluene. The toluene layer was separated, dried and evaporated. The residue was distilled under reduced pressure and then recrystallized from carbon tetrachloride. The yield was $16 \mathrm{~g}$ of a colourless product, m.p. $106^{\circ}$. NMR and gas chromatographic analyses indicated that the product was pure and the NMR spectrum was in agreement with the structure proposed.

2-Bromo-4,5-dimethylbenzoic acid. 2-Bromo-4,5-dimethylbenzonitrile was refluxed with 10 parts of $60 \%$ sulphuric acid for $6 \mathrm{~h}$. The mixture was cooled and the product collected by filtration and recrystallized from toluene. The acid was obtained as colourless crystals with m.p. $195^{\circ}$, lit. 19

4,5-Dimethyl-2-nitroaniline. 3,4-Dimethyl acetanilide was nitrated and the product hydrolysed by the method given by Szantay and Rohaly. ${ }^{13}$

4,5-Dimethyl-2-nitrobenzonitrile. $79 \mathrm{~g}$ of 4,5-dimethyl-2-nitroaniline was dissolved in a hot solution of $120 \mathrm{ml}$ of concentrated hydrochloric acid and $450 \mathrm{ml}$ of water. The mixture was chilled to $0^{\circ}$ and diazotized with $32.2 \mathrm{~g}$ of sodium nitrite dissolved in $95 \mathrm{ml}$ of water. The resulting diazonium solution was slowly added to a mixture of $53.2 \mathrm{~g}$ of cuprous cyanide, $77.3 \mathrm{~g}$ of sodium cyanide, $24 \mathrm{~g}$ of anhydrous sodium carbonate, $360 \mathrm{ml}$ of water, and $120 \mathrm{ml}$ of toluene at a temperature of $0-5^{\circ}$. After standing overnight the mixture was heated to $50^{\circ}$ and then cooled to room temperature. The product was dissolved by the addition of chloroform. The organic layer was separated, dried and evaporated to dryness. The residue was recrystallized from alcohol to yield $57 \mathrm{~g}$ of product with m.p. $166^{\circ}$.

A portion of this product was distilled at reduced pressure and at a temperature slightly above the melting point. The product thus obtained was recrystallized from ethyl acetate to yield pure 4,5-dimethyl-2-nitrobenzonitrile, m.p. $170^{\circ}$. NMR and gas chromatographic analyses indicated that the product was pure and the NMR spectrum was in agreement with the structure proposed.

4,5-Dimethyl-2-nitrobenzoic acid. A mixture of $140 \mathrm{ml}$ of water, $115 \mathrm{ml}$ of conc. sulphuric acid and $21 \mathrm{~g}$ of 4,5-dimethyl-2-nitrobenzonitrile was refluxed for $6 \mathrm{~h}$ and then poured into $450 \mathrm{ml}$ of ice water. The product was collected by filtration, washed with water and recrystallized from toluene. The yield was $16.9 \mathrm{~g}$ and the m.p. $184^{\circ}$; lit. ${ }^{\circ} 184^{\circ}$; methyl ester m.p. $66^{\circ}$, lit..$^{\circ} 66^{\circ}$. The NMR spectrum of this acid was in agreement with that expected for pure 4,5-dimethyl-2-nitrobenzoic acid.

2-Amino-4,5-dimethylbenzoic acid. A portion of 4,5-dimethyl-2-nitro-benzoic acid was hydrogenated in acetic acid using palladium on charcoal as a catalyst. In this way 2 amino-4,5-dimethylbenzoic acid, m.p. $215^{\circ}$, lit. ${ }^{1} 213-214^{\circ}$, was obtained.

2-Bromo-4,5-dimethylnitrobenzene was prepared from 4,5-dimethyl-2-nitroaniline by the Sandmeyer reaction. ${ }^{20}$

4,5-Dimethyl-2-nitrobenzonitrile. A mixture of $3.9 \mathrm{~g}$ of cuprous cyanide, $3.6 \mathrm{~g}$ of pyridine, and $10 \mathrm{~g}$ of 2 -bromo-4,5-dimethylnitrobenzene was heated at $175-180^{\circ}$ for $6 \mathrm{~h}$. It was then allowed to cool to room temperature, crushed and treated with $35 \mathrm{ml}$ of conc. hydrochloric acid, $100 \mathrm{ml}$ of water, and $100 \mathrm{ml}$ of chloroform for $2 \mathrm{~h}$. The organic layer was removed, dried and evaporated. The residue was recrystallized from ethyl acetate to yield $4.3 \mathrm{~g}$ of a product melting at $170^{\circ}$. 
2-Chloroacetyl-4,5-dimethylacetanilide was prepared by Friedel-Craft chloroacetylation of 3,4-dimethyl-acetanilide. ${ }^{15}$

2-Acetamino-4,5-dimethylphenacyl-pyridinium chloride. A mixture of $6 \mathrm{~g}$ of 2-chloroacetyl-4,5-dimethylacetanilide and $17.5 \mathrm{ml}$ of pyridine was heated in a boiling water bath for half an hour. The pyridine was removed at reduced pressure and the residue twice recrystallized from $99.5 \%$ alcohol to yield $6.2 \mathrm{~g}, \mathrm{~m} . \mathrm{p} .271^{\circ}$.

2-Amino-4,5-dimethylbenzoic acid hydrochloride. $24.5 \mathrm{~g}$ of 2-acetamino-4,5-dimethylphenacyl-pyridinium chloride was refluxed for $4 \mathrm{~h}$ with a solution of $27.6 \mathrm{~g}$ of sodium hydroxide in $258 \mathrm{ml}$ of water. After acidification the product was filtered, washed and dried. The hydrochloride was obtained by precipitation with hydrogen chloride in acetone solution. The yield was $11.9 \mathrm{~g}$.

2-Acetyl-4,5-dimethylacetanilide. In a 3-litre three-necked flask fitted with a reflux condenser, a stirrer and a stopper, $207 \mathrm{~g}$ of 3,4-dimethylacetanilide and $166 \mathrm{ml}$ of acetyl chloride were dissolved in $1650 \mathrm{ml}$ of carbon disulphide. $650 \mathrm{~g}$ of $\mathrm{AlCl}_{3}$ was added in portions and the mixture refluxed for one hour and a half. The carbon disulphide layer was decanted off and the residue poured onto ice. The product was collected by filtration and recrystallized from $50 \%$ alcohol. The yield was $201 \mathrm{~g}$ and the m.p. $116^{\circ}$. The NMR spectrum was in agreement with the structure proposed and indicated that the product was pure.

2-Acetamino-4,5-dimethylphenacyl-pyridinium iodide. $199 \mathrm{~g}$ of 2-acetyl-4,5-dimethylacetanilide was dissolved in $405 \mathrm{~g}$ of pyridine. $246 \mathrm{~g}$ of iodine was added to this solution and the mixture heated for half an hour in a boiling water bath. The pyridine was evaporated at reduced pressure and the residue refluxed with one litre of isopropanol and filtered hot. The dark product was recrystallized from methanol. The yield was $196 \mathrm{~g}$ and the m.p. $230^{\circ}$.

2-Acetamino-4,5-dimethylbenzoic acid. $40.9 \mathrm{~g}$ of the above pyridinium compound was heated for $5 \mathrm{~min}$ with a solution of $8 \mathrm{~g}$ of sodium hydroxide in $300 \mathrm{ml}$ of water. The resulting solution was filtered and acidified with $20 \mathrm{ml}$ of concentrated hydrochloric acid. The product was collected by filtration, washed with water and dried. The yield was $17.8 \mathrm{~g}$ of a product melting at $182^{\circ}$. The NMR spectrum was in agreement with the structure proposed and indicated that the product was pure.

2-Amino-4,5-dimethylbenzoic acid hydrochloride. $17.8 \mathrm{~g}$ of 2-acetamino-4,5-dimethylbenzoic acid and $100 \mathrm{ml}$ of conc. hydrochloric acid were refluxed for $2 \mathrm{~h}$. The mixture was chilled and the product collected by filtration, sucked as dry as possible, washed with acetone, and dried in the air. The yield was $14.8 \mathrm{~g}$.

\section{Reactions starting with 3,4-dimethylphthalic an h y dride}

3,4-Dimethylphthalic anhydride was prepared by a two step synthesis from 2,3-dimethylbutadiene, maleic anhydride and sulphur..$^{19}$

2-Amino-4,5-dimethylbenzoic acid was prepared from 3,4-dimethylphthalic anhydride by opening the ring with ammonia and treating the resulting 4,5-dimethylphthalamic acid with sodium hypochlorite by a standard method..$^{21}$ The product was isolated as the hydrochloride by treating an acetone solution with hydrogen chloride. The yield was $33 \%$.

\section{Reactions starting with dimethylisatins}

6,7-Dimethylisatin was prepared from 2,3-dimethylaniline by a standard method. ${ }^{1}$ 2-Amino-3,4-dimethylbenzoic acid was prepared by the oxidation of 6,7-dimethylisatin with hydrogen peroxide in an alkaline solution. ${ }^{1}$ This acid had m.p. $187^{\circ} ; \operatorname{lit}^{1} 184-186^{\circ}$.

4,5-Dimethylisatin and 5,6-dimethylisatin. A mixture of these two compounds was obtained from 3,4-dimethylaniline by a standard method. ${ }^{1}$

2-Amino-4,5-dimethylbenzoic acid was prepared from the above mixture by oxidation with hydrogen peroxide in an alkaline solution and acidification of the resulting solution. ${ }^{1}$ This acid is sparingly soluble in water and can be removed by filtration and recrystallization from alcohol. The m.p. of this acid was $215^{\circ}$; lit. ${ }^{1} 213-214^{\circ}$. 


\section{Reactions starting with 3,4-dimethylacetophenone}

Nitration of 3,4-dimethylacetophenone. The procedure given by Buu-Hô̂, Eckert and Royer $^{8}$ was followed. When the mixture was poured into water a semisolid mass was obtained. This was dissolved in ether, the ether solution dried and the solvent evaporated. A gas chromatographic examination of the residue indicated that it was a mixture of three main components in the proportions 2:1:1. By recrystallization from alcohol the main product $\mathrm{A}, \mathrm{m}$.p. $122^{\circ}$, was easily obtained in a pure state.

The mother liquor was evaporated to dryness and the residue recrystallized from methanol. In this way a fraction $B$, m.p. $70^{\circ}$, was obtained. The mother liquor from the crystallization of product $B$ was evaporated to dryness leaving an oil which was distilled under reduced pressure to yield a liquid C, b.p. $160-165^{\circ}$.

Examination of product $A$ (2-nitro-3,4-dimethylacetophenone). A gas chromatographic examination of product $A$ indicated that this was pure and that it was the main product obtained in the nitration. The melting point $122^{\circ}$ was close to that obtained by Buu-Hoî, Eckert and Royer. ${ }^{8}$ The product must therefore be identical with the main product obtained by them. It was, however, not 4,5-dimethyl-2-nitroacetophenone as stated by these authors but instead 3,4-dimethyl-2-nitroacetophenone. NMR and gas chromatographic analyses indicated that the product was pure and the NMR spectrum was in agreement with the structure proposed.

Another proof for the structure of product $\mathbf{A}$ is obtained from the oxidation with sodium hypochlorite.

3,4-Dimethyl-2-nitrobenzoic acid. A portion of product $\mathbf{A}$ was oxidized with sodium hypochlorite by a standard method. ${ }^{22}$ In this way 3,4-dimethyl-2-nitrobenzoic acid, m.p. $206^{\circ}$, lit. ${ }^{\circ} 206^{\circ}$, was obtained. The methyl ester had m.p. $115-116^{\circ}$, lit..$^{\circ} 114^{\circ}$. The NMR spectrum was in agreement with the structure proposed and indicated that the product was pure.

2-Amino-3,4-dimethylbenzoic acid. A portion of the 3,4-dimethyl-2-nitrobenzoic acid above was hydrogenated using palladium on charcoal as catalyst. In this way 2-amino3,4-dimethylbenzoic acid, m.p. $186^{\circ}$, was obtained. This was identical with the product prepared from 6,7-dimethylisation. ${ }^{1}$ The NMR spectrum was in agreement with the structure proposed and indicated that the product was pure.

2-Amino-3,4-dimethylacetophenone. $30 \mathrm{~g}$ of product $\mathrm{A}$ was suspended in $200 \mathrm{ml}$ of conc. hydrochloric acid and reduced by the addition of $200 \mathrm{~g}$ of $\mathrm{SnCl}_{2}$. The mixture was heated for one hour in a water bath, diluted with water and made alkaline with sodium hydroxide. The product was extracted with methylene dichloride. The resulting solution was dried and evaporated. The residue was recrystallized from dilute methanol. In this way $12 \mathrm{~g}$ of 2-amino-3,4-dimethylacetophenone, m.p. $55^{\circ}$, was obtained. This product is certainly not identical with the product melting at $131^{\circ}$ reported by Buu-Hoî, Eckert and Royer to be obtained from the same starting material by the same method. The NMR spectrum was in agreement with that expected for pure 2-amino-3,4-dimethylacetophenone.

Examination of product $B$. A gas chromatographic examination of product $\mathbf{B}$ indicated that it was a mixture of $30 \%$ of product $A$ and $70 \%$ of another product that was shown to be 4,5-dimethyl-2-nitroacetophenone. Since the mixture was impossible to separate by recrystallization a part of it was reduced.

2-Amino-4,5-dimethylacetophenone. A portion of product $\mathrm{B}$ was hydrogenated using palladium on charcoal as catalyst. By recrystallization from alcohol 2-amino-4,5-dimethylacetophenone, m.p. $127^{\circ}$, lit. $12125-127^{\circ}$, was obtained. NMR analysis indicated that the product was pure and the NMR spectrum was in agreement with the structure proposed.

2-Acetamino-4,5-dimethylacetophenone. A portion of the product above was treated with acetic anhydride. Dilution with water and recrystallization from $50 \%$ alcohol gave 2-acetamino-4,5-dimethyl-acetophenone, m.p. $116^{\circ}$, identical with that obtained by the Friedel-Crafts acetylation of 3,4-dimethylacetanilide.

4,5-Dimethyl-2-nitroacetophenone. 2-Amino-4,5-dimethylacetophenone, the material obtained by the reduction of product $B$, was diazotized in fluoroboric acid, and the diazonium fluoroborate treated with sodium nitrite and copper powder. In this way 4,5-dimethyl-2-nitroacetophenone, m.p. $80^{\circ}$, was obtained. This is certainly not identical with the product of m.p. $120^{\circ}$ obtained by Buu-Hoî, Eckert and Royer ${ }^{8}$ in the nitration

Acta Chem. Scand. 21 (1967) No. 4 
of 3,4-dimethylacetophenone. A gas chromatographic analysis indicated that the product was over $95 \%$ pure and had the same retention time as one of the three main peaks obtained from the crude nitration product and the same as the main peak of product $B$. The NMR spectrum was in agreement with that expected for pure 4,5-dimethyl-2-nitroacetophenone.

Examination of product $C$. A gas chromatographic examination of product $\mathbf{C}$ gave the result that it was a mixture containing about $17 \%$ of 3,4-dimethyl-2-nitroacetophenone, $15 \%$ of 4,5-dimethyl-2-nitroacetophenone, and $63 \%$ of a third product.

4,5-Dimethyl-3-nitrobenzoic acid. A portion of product $\mathrm{C}$ was oxidized with sodium hypochlorite by a standard method. ${ }^{22}$ On careful acidification the first of the three isomeric acids to be precipitated is 4,5-dimethyl-3-nitrobenzoic acid. It was purified by recrystallization from alcohol. This acid had m.p. $199^{\circ}$; lit..$^{\circ} 199^{\circ}$. The methyl ester had m.p. $62^{\circ}$, lit..$^{\circ}$. The NMR spectrum was in agreement with the structure proposed and indicated that the product was pure.

The authors are indebted to Dr. Robert Carter for the NMR analyses and for his kind revision of the English of this manuscript.

\section{REFERENCES}

1. Baker, B. R., Schaub, R. E., Joseph, J. P., Mc Evoy, F. J. and Williams, J. H. J. Org. Chem. 17 (1952) 149.

2. Olah, G. A., Moffatt, M. E., Kuhn, S. J. and Hardie, B. A. J. Am. Chem. Soc. 86 (1964) 2198.

3. Silverstein, R. M. and Bassler, G. C. Spectrometric Identification of Organic Compounds, Wiley, New York-London-Sydney 1964, p. 60.

4. Krüger, A. Ber. 18 (1885) 1755.

5. Dokukina, A. F. and Koton, M. M. Zh. Obshch. Khim. 29 (1959) 2201.

6. Org. Syn. III, p. 138.

7. Birch, S. F., Dean, R. A., Fidler, F. A. and Lowry, R. A. J. Am. Chem. Soc. 71 (1949) 1364.

8. Buu-Hô̂, Ng. Ph., Eckert, B. and Royer, R. J. Org. Chem. 17 (1952) 1000.

9. Kerfanto, M. and Raphalen, D. Compt. Rend. 258 (1964) 6441.

10. Lyon, D. R., Mann, F. G. and Cookson, G. H. J. Chem. Soc. 1947668.

11. Mann, F. G. and Watson, J. J. Chem. Soc. 1947512.

12. Rosowsky, A., Protopapa, H. K. and Modest, E. J. J. Org. Chem. 30 (1965) 287.

13. Szantay, C. and Rohaly, J. Periodica Polytech. 8 (1964) 9.

14. Mills, W. H. and Nixon, I. G. J. Chem. Soc. 19302524.

15. Kunckell, F. and Schneider, H. J. Pract. Chem. 86 (1912) 430.

16. Kröhnke, F. Angew. Chem. 65 (1953) 607.

17. Hinkel, L. E., Ayling, E. E. and Walters, T. M. J. Chem. Soc. 19341946.

18. Badger, C. M., Cook, J. W. and Goulden, F. J. Chem. Soc. 194017.

19. Stapleton, G. and White, A. I. J. Am. Pharm. Assoc. 43 (1954) 199.

20. van Berk, P., van Langen, J. O. M., Verkade, P. E. and Wepster, B. M. Rec. Trav. Chim. 75 (1956) 1152

21. Houben, J. and Weyl, T. Methoden der Organischen Chemie 11/1, Thieme, Stuttgart 1957, p. 860.

22. Houben, J. and Weyl, T. Methoden der Organischen Chemie 8, Thieme, Stuttgart 1952 , p. 415.

Received December 22, 1966. 